\title{
A new turtle species of Brodiechelys from the Early Cretaceous of Spain: Systematic and palaeobiogeographic implications
}

Adán Pérez-García, José Miguel Gasulla, and Francisco Ortega

Acta Palaeontologica Polonica 59 (2), 2014: 333-342 doi: http://dx.doi.org/10.4202/app.2012.0059

Brodiechelys brodiei is an Early Cretaceous turtle from Great Britain, the only species of the genus. This taxon has been shown in recent phylogenies to be closely related to Xinjiangchelyidae and therefore could be the only representative of this group in Europe. Here, we present several specimens from the Early Cretaceous Maestrazgo Basin, in the Iberian Range of Spain attributed to the British genus, and to a new species, Brodiechelys royoi . This discovery shows that, as previously observed with terrestrial turtles, some freshwater turtle taxa had a wide European distribution during the Early Cretaceous, being present in both Britain and the Iberian Peninsula. This study sheds new light on the phylogenetic position of this enigmatic genus, supporting its attribution to Xinjiangchelyidae, a clade whose presence has been previously confirmed exclusively from the Middle Jurassic to Early Cretaceous of Asia. We propose that another recently identified taxon from the Iberian Peninsula (i.e., Larachelus morla) is also a member of this clade. Recent studies have identified several continental taxa of the clade that included the members of "Macrobaenidae" and "Sinemydidae" in Europe. This study provides new evidence of close relationships between the Early Cretaceous turtle faunas from Europe and Asia.

Key words: Testudines, Pan-Cryptodira, Xinjiangchelyidae, Brodiechelys, Cretaceous, Europe, Spain.

Adán Pérez-García [paleontologo@ gmail.com], Departamento de Paleontología, Facultad de Ciencias Geológicas, Universidad Complutense de Madrid, José Antonio Novais 2, 28040 Ciudad Universitaria, Madrid, Spain; José Miguel Gasulla [jm.gasulla@gmail.com], Unidad de Paleontología, Departamento de Biología, Universidad Autónoma de Madrid, Darwin 2, 28049 Madrid, Spain; Francisco Ortega [아tega@ccia.uned.es], Grupo de Biología Evolutiva, Facultad de Ciencias, UNED, Senda del Rey 9, 28040 Madrid, Spain.

This is an open-access article distributed under the terms of the Creative Commons 
Attribution License (for details please see creativecommons.org), which permits unrestricted use, distribution, and reproduction in any medium, provided the original author and source are credited.

PoFif Full text $(361.2 \mathrm{kB})$ 